\title{
Mechanisms of structure formation underlying the creaming reaction in a processed cheese model system as revealed by light and transmission electron microscopy
}

\author{
Almut H. Vollmer, ${ }^{1 *}$ (1) Ingrun Kieferle, ${ }^{2}$ Nabil N. Youssef, ${ }^{1}$ and Ulrich Kulozik ${ }^{2}$ (]) \\ ${ }^{1}$ Department of Nutrition, Dietetics, and Food Sciences, Utah State University, Logan 84322-8700 \\ ${ }^{2}$ Chair of Food and Bioprocess Engineering, TUM School of Life Sciences, Technical University of Munich, 85354 Freising, Germany
}

\begin{abstract}
The "creaming reaction," a general thickening of the molten cheese mass during the manufacture of processed cheese, which is often seen to occur in a stepwise fashion, affects the viscosity and texture of the finished product. Thus, this phenomenon is of critical importance for the processed cheese industry, yet mechanisms underlying the structure formation in this surprisingly complex and dynamic food system are only poorly understood. Using a model system consisting of micellar casein concentrate, vegetable oil, water, and a mixture of melting salts, we followed the characteristic viscosity profile with its primary and secondary increase over time. A rheometer equipped with a custom-made cup geometry was used, which served as a mini-reaction vessel to simulate the conditions during the manufacture of processed cheese. The mixture was subjected to constant heat $\left(90^{\circ} \mathrm{C}\right)$ and stirring $(7.93 \mathrm{rpm})$, comparable to processed cheese cooking, for up to $410 \mathrm{~min}$. At specific time points, samples were taken, and the micro- and ultrastructure was investigated with light and transmission electron microscopy. Results from our extensive study uncovered the following key steps: (1) a decrease in fat globule size with concomitant increase in the number of fat globules, which were also more evenly distributed; (2) a progressive separation of the casein matrix into fibrillogenic and nonfibrillogenic fractions; (3) formation of fibrils and their higher-order structuring followed by their partial degradation; and (4) increasing interactions of the fibrils with the fat globule surface leading to a higher degree of emulsification. Of these different observations, results indicate that after the caseins dissociated under the influence of the melting salts, protein-protein interactions were the primary driver of the structure formation and thus contributed to the initial viscosity increase. Fat globules
\end{abstract}

Received December 24, 2020.

Accepted April 12, 2021.

*Corresponding author: almut.vollmer@usu.edu were involved in the structure formation at later time points. Therefore, fat-protein interactions in addition to continued protein-protein interactions were assumed to contribute to the secondary viscosity increase. An updated processed cheese creaming model is presented. The use of the term "texturization" instead of "creaming" is proposed.

Key words: creaming reaction, electron microscopy, fibrils, multistep structure formation, texturization

\section{INTRODUCTION}

Compared with natural cheese, processed cheese is a relatively new category of dairy product. Driven by the desire to increase the shelf life of natural cheese, processed cheese was invented a little over $100 \mathrm{yr}$ ago independently in Europe and the United States (Zehren and Nussbaum, 1992). Initially, processed cheese was made by adding only citrate salts, phosphate salts, or both to comminuted, traditionally manufactured cheese that was then heated (typically $>80^{\circ} \mathrm{C}$ ) under constant stirring to form a homogeneous molten mass. Upon cooling, this mass set to a dairy product that not only was more shelf stable, even at room temperature, but also displayed different textural and sensory characteristics than the original cheese it was made from. This, along with modifications to formulations and process parameters, led to a rapid increase in the application range and hence popularity (Zehren and Nussbaum, 1992). Although today's manufacture of processed cheese is principally straightforward, it is far from being foolproof, and even minor deviations from established formulations or process parameters can result in products with undesired textural or organoleptic attributes with potentially large losses in sales and profit. The structure formation during the manufacture of these kinds of products is not well understood, which can lead to high degrees of product variability affecting consumer acceptance. In particular, the so-called creaming reaction, as it is commonly referred to in the processed cheese industry, deserves special attention 
here. Simply put, the "creaming reaction" or "creaming effect" describes an often stepwise increase in viscosity of the molten mass during and after the cooking step before filling into tubes or cooling in thin layers for the production of processed cheese slices (Guinee et al., 2004; Fu et al., 2018). This is not to be confused with the migration of fat droplets in unhomogenized milk, a process also known as "creaming." Creaming in the context of processed cheese products determines the viscosity and texture of the final product and therefore can, in principle, be used to monitor and modify the textural properties of the final product. "Undercreamed" processed cheese is said to be too soft, whereas "overcreamed" processed cheese is characterized by a hard, grainy texture with decreased melting properties (Berger et al., 1998). "Well-creamed" processed cheese, as the name implies, exhibits the expected texture and melting characteristics of a particular processed cheese product.

From a physicochemical point of view, processed cheese can be considered as an oil-in-water emulsion that rapidly forms as a result of the action of the melting or emulsifying salts (sodium citrates and sodium phosphates) on the protein phase. The main function of these salts is to sequester calcium, an essential structural element in the casein matrix and the casein micelle, respectively (Berger et al., 1998). In the presence of melting salts and aided by temperature and stirring, the caseins $\left(\alpha_{\mathrm{S}^{-}}-\mathrm{CN}, \alpha_{\mathrm{S}^{2}} \mathrm{CN}, \beta-\mathrm{CN}\right.$, and $\left.\kappa-\mathrm{CN}\right)$ dissociate from the cheese matrix, or from the casein micelle when micellar casein concentrate is used. They hydrate, swell, and solubilize, which allows them to quickly adsorb to the fat globule surface, thereby leading to a stable emulsion (Guinee et al., 2004).

The attractiveness of processed cheese products with their wide range of applications is somewhat curtailed by the surprising complexity of the system as a consequence of using a broad range of incoming raw materials (soft, semihard or hard cheeses in varying ratios and at different cheese-ripening levels) with hard-to-define physicochemical properties of the mixture (i.e., degree of proteolysis and thus concentration of intact casein), and the phenomenon of the creaming reaction. In an extensive study by Lenze et al. (2019) on the compositional factors and process parameters affecting the creaming reaction, the authors clearly demonstrated this point. Using a rheometer with a 2-blade stirrer in a custom-made cup geometry to mimic the manufacture conditions in an industrial tank, they followed the changes in apparent viscosity in real time in both a cheese system and a model system. The observed viscosity profiles were characterized by an initial phase with relatively low viscosities followed by an exponential rise, a plateau phase, and a second exponential rise. This characteristic (i.e., stepwise) profile changed at times drastically in relation to changes in the fat content, fat pretreatment, protein concentration, and addition of rework (cheese that had already undergone the processed cheesemaking procedure). Other factors, such as temperature, stirring speed, protein source, $\mathrm{pH}$, and type of emulsifier were also shown to influence the shape of the viscosity profile (Röck, 2010). Although of high practical relevance to the processed cheese industry, the underlying mechanisms leading to the creaming reaction; that is, the increase in viscosity, have seen only limited attention. The formation of a finely emulsified fat phase in the system containing cheddar cheese, as observed by light microscopy in samples taken during the creaming reaction, led Lenze et al. (2019) to confirm earlier conclusions that the degree of emulsification was one possible mechanism (Rayan et al., 1980; Kalab et al., 1987). In the same study, transmission electron microscopy (TEM) images of freeze-etched samples from the model system showed subtle changes in the protein phase, and the authors expanded their view to include protein interactions as another possible mechanism. This had already been put forward by Heertje (1993) after analyzing chemically fixed samples that were taken during the processing time with TEM, which showed slightly more pronounced changes in the protein phase, particularly toward the end of the processing time. Lee et al. (2003) added additional insights to the conclusion drawn by Heertje (1993) when they studied the rheological behavior and microstructure of traditional processed cheese and fat-free model processed cheese. They postulated that protein interactions were the main driver of the structure formation based on the recorded characteristics of the viscosity increase in both the processed cheese of a typical formulation (i.e., with fat) and the fat-free model processed cheese. However, peak viscosities in the fat-free system were lower than in the typical formulation, were reached later during processing, and markedly decreased toward the end of processing. These results were interpreted by ascribing fat a secondary role; that is, as a modifier or plasticizer. This contradicts Berger et al. (1998), who stated that the creaming reaction could only occur in the presence of fat.

Although results from these studies comprise a good starting point, they do not conclusively show the exact mechanisms underlying the structure formation responsible for the observed viscosity change during the creaming reaction. An understanding of the creaming reaction at its mechanistic level is indispensable for the design of cheese manufacturing lines to better control and standardize the processing conditions during and after the cooking step. This would reduce product variability and might also assist in the development of 
novel processed cheese products. The aim of our study, therefore, was to investigate the emulsification process and protein interactions in more detail by high-resolution TEM augmented by light microscopy (LM) of samples taken along the creaming reaction. We built on the processed cheese model system used by Lenze et al. (2019) with some modifications to reduce complexity and, therefore, the number of possible confounding factors. We chose a set of processing parameters that was shown to lead to the characteristic profile but with a higher sampling frequency to obtain a better picture of the structural changes taking place during the creaming reaction and how they are related to each other.

\section{MATERIALS AND METHODS}

\section{Experimental Setup}

All experiments were performed with a rheometer (MCR 702, Anton Paar GmbH) in speed-control mode. A custom-made stainless-steel geometry, as shown in Figure 1, was used. It consisted of a cup with an inner diameter of $65.9 \mathrm{~mm}$ and a height of $30.0 \mathrm{~mm}$. The cup was closed with 2 removable lid halves that fit securely around the measuring bob axis without impeding its movement. A lip on the lower side of each lid half enclosed the top of the cup when fully assembled and thus prevented lateral movement and also minimized evaporational loss from the sample. A custom-made 2-blade stirrer $(60.5 \mathrm{~mm} \times 10.2 \mathrm{~mm} \times 1 \mathrm{~mm})$ connected to the measuring bob axis (without Toolmaster).

\section{Composition of the Processed Cheese Model System}

Ingredients of the processed cheese model system are listed in Table 1 with their respective percent amounts and target values for $\mathrm{pH}$ and $\mathrm{DM}$ content. The protein source was micellar casein concentrate (MCC) powder, which was manufactured according to Dumpler (2018) at

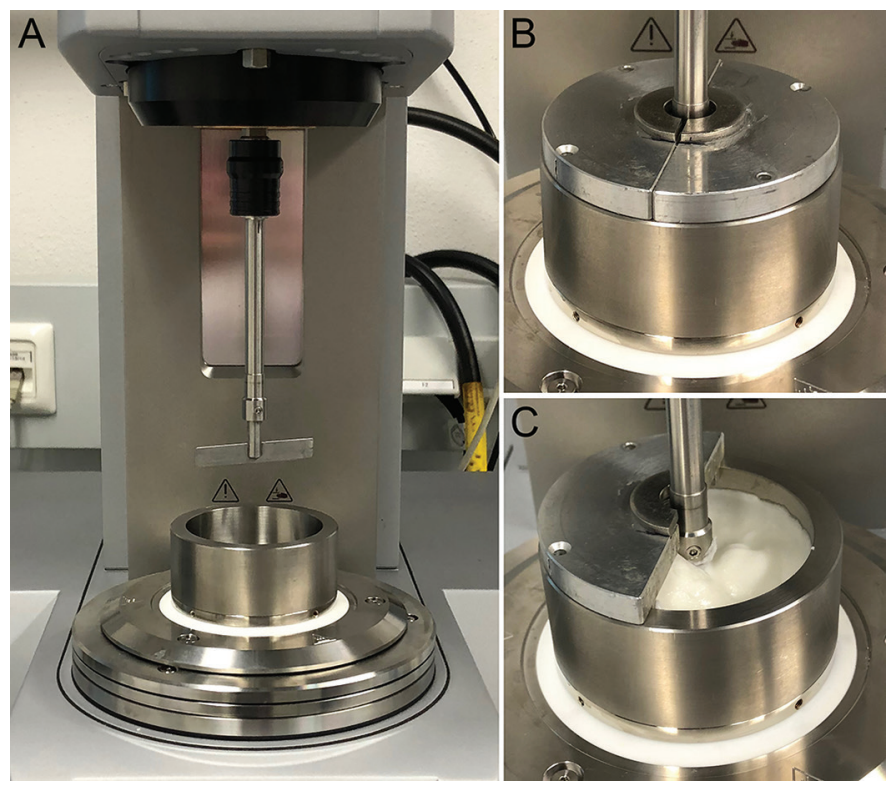

Figure 1. (A) Rheometer with custom-made geometry and 2-blade stirrer in (B) fully closed position and (C) with one lid-half removed during a practice run for presentation purposes.

the Technical University of Munich, Germany. In brief, $300 \mathrm{~L}$ of skim milk (Molkerei Weihenstephan GmbH \& Co. KG) was concentrated by microfiltration at $50^{\circ} \mathrm{C}$ and diafiltered against simulated milk ultrafiltrate. The concentrate was spray-dried at $190^{\circ} \mathrm{C}$ and $80^{\circ} \mathrm{C}$ (inlet and outlet temperatures, respectively) and stored in air-tight dark plastic bags at $4^{\circ} \mathrm{C}$ until further use. The protein content of the MCC powder was quantified by reversed phase-HPLC to be $85 \%$, of which $98 \%$ was casein and $2 \%$ was whey protein (Dumpler et al., 2017). The fat source was sunflower oil purchased from a local grocery store, with a total combined unsaturated fatty acid content of $85.4 \%$ as quantified by gas chromatography analysis at the Technical University of Munich. Salts used were of analytical grade and purchased from either Merck KGaA or Carl Roth GmbH.

Table 1. Formulation of the processed cheese model system with target values for $\mathrm{pH}$ and DM content

\begin{tabular}{llc}
\hline Ingredient & Source (chemical formula) & $\begin{array}{c}\text { Amount, \% } \\
(\text { wt } / \text { wt) }\end{array}$ \\
\hline Protein & Micellar casein concentrate & 18.42 \\
Fat & Sunflower oil & 19.59 \\
Water & Milli-Q water & 58.48 \\
Emulsifying salt & Trisodium citrate, dibasic $\left(\mathrm{Na}_{3} \mathrm{C}_{6} \mathrm{H}_{5} \mathrm{O}_{7} \cdot \mathrm{H}_{2} \mathrm{O}\right)$ & 0.44 \\
& Disodium phosphate dihydrate $\left(\mathrm{Na}_{2} \mathrm{HPO}_{4} \cdot 2 \mathrm{H}_{2} \mathrm{O}\right)$ & 0.44 \\
Acidulant & Pentasodium triphosphate $\left(\mathrm{Na}_{5} \mathrm{P}_{3} \mathrm{O}_{10}\right)$ & 1.75 \\
Target pH & Citric acid monohydrate $\left(\mathrm{C}_{6} \mathrm{H}_{8} \mathrm{O}_{7} \cdot \mathrm{H}_{2} \mathrm{O}\right)$ & 0.88 \\
Target DM & 5.88 & \\
\hline
\end{tabular}




\section{Preparation and Analysis of the Premix}

For each experiment, a batch (referred to as premix) of $68.5 \mathrm{~g}$ was freshly prepared by first dissolving the salts with salt-free water in a glass beaker. The mix was then added to the sunflower oil (in a second glass beaker) and briefly pre-emulsified with a dispersing instrument (T25 digital Ultra-Turrax, IKA Werke GmbH \& Co. KG). Last, the MCC powder was added and dispersed for 1 min at speeds up to 10,400 rpm. pH values of the premix were determined in duplicates using a solid-state pH electrode (InLab Solids, Mettler Toledo), and DM was measured, also in duplicates, using a rapid moisturizer/solid analyzer (Smart 6, CEM GmbH). The $\mathrm{pH}$ of the premix was $5.88 \pm 0.02$ (mean $\pm \mathrm{SD}$ ), and the DM content was $40.3 \% \pm 0.2($ mean $\pm \mathrm{SD})$.

\section{Heat-Shear Treatment and Sampling}

Forty grams of the freshly made premix was transferred to the preheated $\left(90^{\circ} \mathrm{C}\right)$ rheometer cup, the measurement position of the stirrer set to $160 \mu \mathrm{m}$ above the bottom of the cup, the 2 lid halves carefully placed on top of the cup so as to not impair the movement of the measuring bob axis, and the run was started. The mix was stirred and thus sheared (temperature, $90^{\circ} \mathrm{C}$; rotational speed, $7.93 \mathrm{~min}^{-1}$ ) for up to 410 min, and the change in torque exerted on the stirrer of the custom-made geometry, as an indirect measure of viscosity, was recorded every $15 \mathrm{~s}$. At certain time points $(15,50,175,275,315$, and $410 \mathrm{~min})$, reflective of characteristic phases in a typical viscosity curve as determined by Lenze et al. (2019) and elsewhere (data not shown), the rotational speed was reduced $(0.218$ $\min ^{-1}$ ) to allow for even distribution of the mixture in the rheometer cup, followed by cooling of the sample to $4^{\circ} \mathrm{C}\left(0.580^{\circ} \mathrm{C} \mathrm{min}^{-1}\right)$. This slow cooling rate was chosen to mimic conditions in a typical cooling chamber. Once the mixture had reached the final temperature, the geometry was disassembled, and samples were taken for the determination of $\mathrm{pH}$ and DM content as already described. Samples were also taken for LM and TEM and processed as described below. Due to the destructive nature of sampling, each sample originated from an independent run with each run performed twice for a given time point, totaling 12 samples.

\section{Light and Transmission Electron Microscopy}

Materials. When not otherwise stated, materials used for sample preparation were obtained from Electron Microscopy Sciences.

Sample Preparation. The cold mixture was removed from the cup with a spatula, placed on a sheet of dental wax, and several strips $(\sim 3 \mathrm{~mm} \times 3 \mathrm{~mm} \times$
$10 \mathrm{~mm}$ ) were cut with a razor blade from the center (to avoid potential edge effects) and transferred to vials containing cold fixative (formaldehyde/glutaraldehyde, $2.5 \%$ each in $0.1 M$ sodium cacodylate buffer, $\mathrm{pH} 7.4$ ). A small piece of sponge (saturated in fixative) was carefully placed below the meniscus to guarantee complete immersion of the sample in the fixation agent. This was particularly important for samples taken early during the time course due to trapped air pockets within the sample. Samples were fixed at room temperature for at least $2 \mathrm{~h}$ and then stored in fixative at $4^{\circ} \mathrm{C}$ before shipping to the United States and processing according to Vollmer et al. (2019). Thin sections ( $500 \mathrm{~nm})$ were imaged on a digital optical microscope (VXH-5000, Keyence), and ultrathin sections $(\sim 70 \mathrm{~nm})$ were examined with a transmission electron microscope (JEM 1400 Plus, JEOL USA Inc.) operated at $120 \mathrm{kV}$ and equipped with a high-performance CCD camera (Orius SC1000, Gatan Inc.).

Imaging and Analysis. Three to 5 sections from 2 to 3 randomly selected polymerized blocks per time point and replicate were analyzed, and images covering a wide range of magnifications $(500 \times-50,000 \times)$ were taken from up to 15 fields of view. In total, over 1,800 images were recorded for this study, and the most representative images were selected for presentation. When necessary, brightness and contrast levels of micrographs were adjusted in Adobe Photoshop 2020 (Adobe), but no other image modification process was used.

\section{Statistical Analysis}

Changes in DM content and pH were analyzed with 2-way ANOVA followed by Sidak's test for multiple comparisons. Significance was declared for $P$-values $<0.05$. All analyses were performed in Prism 6 (GraphPad Software Inc.).

\section{RESULTS}

\section{Rheology: Viscosity Profile of the Model Processed Cheese}

Changes in the viscosity of the model processed cheese during the creaming reaction were monitored with a rheometer by measuring the torque exerted on the stirrer of the custom-made geometry. The viscosity profile, as seen in Figure 2, was characterized by an initiation phase in which torque values rapidly decreased from $\sim 12$ to $\sim 1 \mathrm{mN} \cdot \mathrm{m}$ in response to the temperature increase from room temperature to the set temperature of $90^{\circ} \mathrm{C}$. The initiation phase was followed by a gradual first increase in torque values, which reached a plateau of $\sim 6 \mathrm{mN} \cdot \mathrm{m}$ at approximately $200 \mathrm{~min}$ into the processing time, followed by a second, more rapid increase. Torque 
values started to fluctuate strongly after 320 min until the end of the time course with maximum values of $\sim 36$ $\mathrm{mN} \cdot \mathrm{m}$. These fluctuations were likely caused by parts of the thickened mixture occasionally adhering to the measuring bob axis and randomly dislodging, similar to thick bread dough sticking to a mixer dough hook and periodically being released. Visual inspection at the end of the processing time confirmed the presence of some of the mixture on the bob axis above the stirrer.

Some minor differences exist between the viscosity profile presented here and the characteristic course of structure formation published by Lenze et al. (2019). These differences are likely attributable to differences in the experimental set-up; that is, no premix was prepared in the study by Lenze et al. (2019). Rather, all ingredients were directly added to the cup, and the run was started. We hypothesized that dissolving the salts in water before adding the oil and protein powder, as we did, was beneficial for a homogeneous distribution of all ingredients. Lenze et al. (2019) used rennet casein to simulate the type of protein present in processed cheese, whereas we used native casein in the form of micellar casein concentrate powder. Röck (2010) had shown earlier that there was no discernable difference between the 2 protein sources in regard to their creaming behavior. However, we wanted to exclude any chance of structural variability effected by the degree of proteolysis found in natural cheese (Berger et al., 1998). We further decided to replace the milk fat with sunflower oil to eliminate possible confounding effects arising from the milk fat globule membrane and associated proteins, and for practical reasons based on the long shelf life of the oil.

In the end, and as anticipated, the viscosity profile was generally comparable to that seen in Lenze et al. (2019) in that there was an initiation phase, an exponential phase I, a plateau phase, and an exponential phase II. Thus, a similar structure formation process compared with the earlier studies was achieved. To examine the structural changes reasoned to be responsible for the distinctive changes in the viscosity, samples taken at specific time points during the creaming reaction were analyzed first with LM and then with TEM.

\section{LM: Structure Formation in the Model Processed Cheese}

In samples taken after 15 and 50 min of processing time and prepared for LM, fat globules of various sizes were observed as inhomogenously distributed clusters within the casein matrix (Figure $3 \mathrm{~A}$ and $\mathrm{B}$ ). Trapped air pockets were abundant, which explains the floating behavior of those samples during the initial steps of chemical processing. Pronounced changes took place

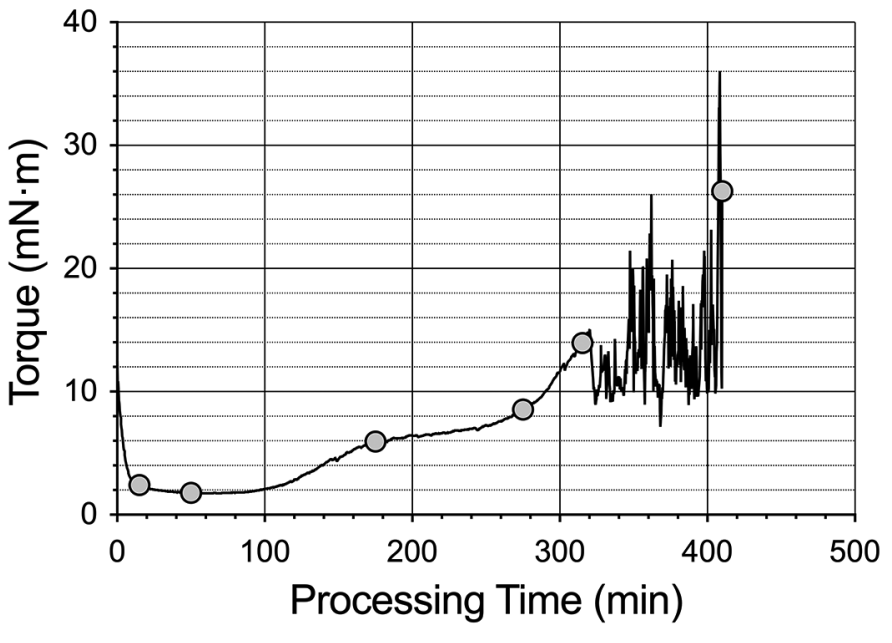

Figure 2. Representative viscosity profile of the hot model processed cheese melt. Circles indicate sampling times for subsequent analysis by light microscopy and transmission electron microscopy ( 15 $50,175,275,315$, and $410 \mathrm{~min})$.

within the protein matrix as it started to separate into areas with slightly different staining patterns after 175 min (Figure 3C, asterisks). Qualitative assessment of the micrographs indicated that the fat globule diameter decreased over time, particularly after 275 min (Figure $3 \mathrm{D})$, whereas the number of fat globules increased, leading to a homogeneous distribution of the fat at the end of processing (Figure 3F). After 275 min, spherical to ovoid and otherwise irregularly shaped lighter blue areas amid the darker blue casein matrix were clearly visible (Figure 3D) and continued to be throughout the remainder of the time course.

To our knowledge, this progressive separation of the casein matrix has not been documented before in other processed cheese systems. We believe that this could have contributed to the observed increase in apparent viscosity. To understand the nature of these distinct areas and the state of emulsification, samples were analyzed by high-resolution TEM.

\section{TEM: Structure Formation in the Model Processed Cheese}

Low-magnification TEM images of thin-sectioned material from samples taken along the creaming reaction are presented in Figure 4. In contrast to LM images, TEM images are captured as black-and-white images because TEM relies on high-energy electrons rather than on photons to form an image after the interaction with the sectioned and contrasted material. Objects are typically identified based on a combination of morphology and electron density, the latter being a reflection of the material and its atomic weight as well as the high atomic weight of the stains used to 

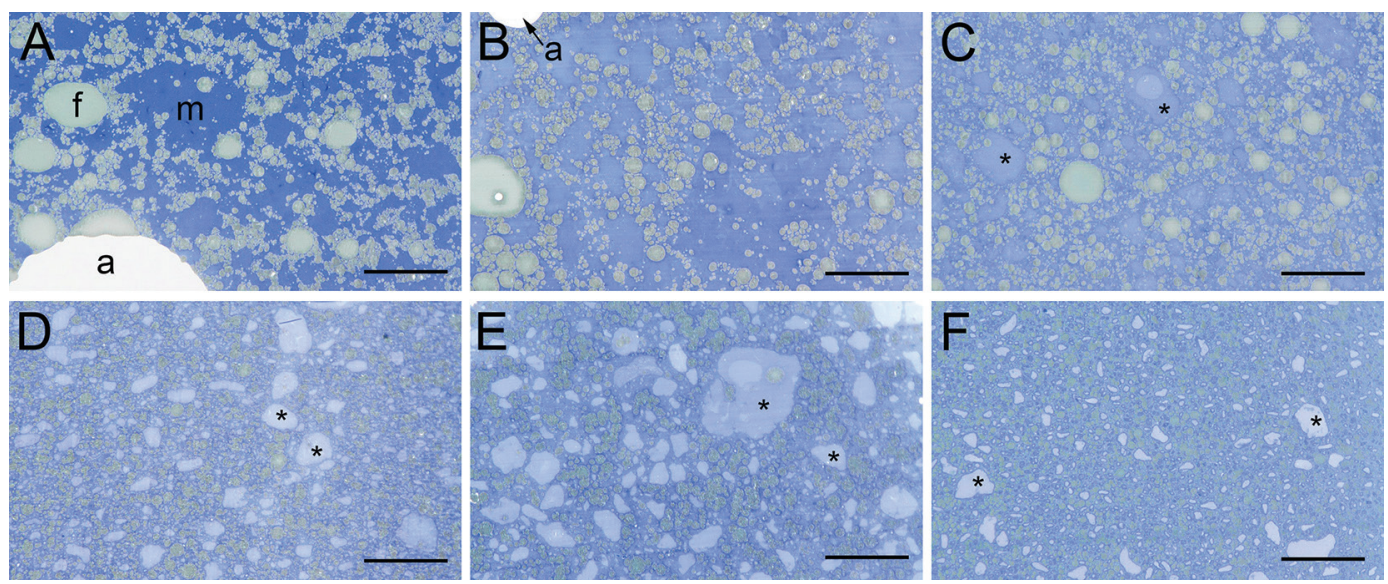

Figure 3. Light micrographs of model processed cheese showing a change in the degree of emulsification (i.e., fat globule size, number, distribution) as well as a progressive separation of the casein matrix into areas with distinctly different staining patterns during processing (asterisks). (A) $15 \mathrm{~min}$, (B) $50 \mathrm{~min}$, (C) $175 \mathrm{~min}$, (D) $275 \mathrm{~min}$, (E) $315 \mathrm{~min}$, (F) $410 \mathrm{~min}$; a = air pocket; f = fat; $\mathrm{m}=$ casein matrix. Instrumental magnification at $500 \times$, with the scale bar representing $100 \mu \mathrm{m}$.

improve contrast with otherwise very contrast-poor materials of biological origin (Bozzola and Russell, 1999). That being said, fat globules in Figure 4 are visible as electron-dense (dark gray) spherical objects of varying size that predominantly clustered together. The highly electron-dense appearance of the fat globules was reflective of the strong interaction of osmium tetroxide with the unsaturated fatty acids of the sunflower oil used in this study. The casein matrix in the early stages of the creaming reaction was mostly uniform and less electron-dense (lighter gray) than the fat globules. As the field of view is too small even at the lowest magnification used in the TEM $(500 \times)$, and some fat globules were initially larger than $50 \mu \mathrm{m}$, the decrease in fat globule diameter can only be partially observed in the presented micrographs. The separation of the protein matrix, on the other hand, can be easily followed, and first signs were already evident after 50 min of processing time (this was barely noticeable in LM images after 175 min of processing time) with the appearance of slightly inhomogeneous areas, sometimes with a thin strip of higher electron density at their periphery (Figure 4B). During processing, these areas gained in size and prominence with concurrent losses of the electron density in the central region. At the end of processing, these areas were bordered by a broad band of more electron-dense material, which was also distinct from the original casein matrix (Figure $4 \mathrm{~F}$ ). Fat globules were typically smaller than during the early phases. At no time during the experiments did fat globules show any signs of large-scale coalescence, indicating the persistence of a stable emulsion.

In the following sections, representative TEM images from each time point at high magnification will be pre- sented and described in more detail to highlight the different components of the structure formation process.

TEM of Samples Taken at 15 Minutes. As seen from the TEM images at low magnification (Figure 4), fat globules initially formed large clusters throughout the casein matrix (Figure 5A). Fat globules were often bordered by a thin layer of protein (casein), which was visible at higher magnification as a crisp, dark line when sectioned in full equatorial plane (Figure 5B, arrowheads). Above and below the equatorial plane, the same dark line appeared as diffusely granular extensions of the casein matrix (Figure 5C). Thus, fat globules in even very close proximity to each other did not coalesce.

The casein matrix was overall characterized by a uniformly coarse granular structure (Figure 5B) reflective of the destabilizing action of the melting salts on the casein micelles resulting in their rapid dissociation and dispersion. However, small areas of very low electron density were frequently seen in association with fat globules (Figure 5A). Upon closer inspection, these areas contained casein micelles that still had retained some of their characteristic morphology amid voids into which fine, irregular protein strands protruded, which could be traced back to the micelles (Figure 5C, arrow). As a consequence, the oil-water interface was slightly less emulsified in these regions.

Although the protein matrix in most areas was uniformly coarse, as seen in Figure 5B, some regions of the sample contained areas of slightly different electron density with numerous electron-opaque small inclusions (Figure 5D). These differences were easy to see at low magnification, but they were very difficult to discern at high magnification, with the only difference 
being a slightly higher incidence of minute, very dark electron-dense protein particles (Figure 5E and F). As will be evident from TEM images taken at later time points, these areas constituted precursors of the beginning matrix separation, which means that the proteins within the casein matrix had started to separate even earlier than was apparent from low-magnification TEM images at 50 min (Figure 4B).

TEM of Samples Taken at 50 Minutes. Fifty minutes after the start of processing, which coincided with the lowest recorded viscosity during the time course, samples of model processed cheese still contained various areas in which the casein micelles had not fully dissociated (Figure $6 \mathrm{~A}$ and $\mathrm{B}$, arrowheads). The protein separation within the casein matrix was evident now, and differences were more clearly distinguishable at both lower and higher magnification. The minute, very electron-dense particles that were a characteristic component of the protein separation within the casein matrix formed loose aggregates at the region bordering the casein matrix (Figure 6D). This gave the impression, at low magnification, of a dark band encircling the newly separated area (Figure 6A). The coarsely granulated structure of the casein matrix, on the other hand, largely had not changed. However, individual fibril-like structures started to appear throughout the matrix (Figure $6 \mathrm{~B}$ and $\mathrm{C}$, arrows).

TEM of Samples Taken at 175 Minutes. After 175 min of processing, the viscosity curve had entered a plateau after the first initial increase; no evidence was observable anymore of any undissociated casein micelles. Instead, the casein matrix was filled with a multitude of slightly curved fibrils of varying length set against the coarsely granulated background of the casein matrix (Figure 7). The fibrils displayed a pronounced dark-light-dark pattern when seen in longitudinal plane (Figures $7 \mathrm{C}$ to $\mathrm{E}$ ). The newly separated protein areas were clearly distinct from the surrounding casein matrix by way of their lower electron density compared with the latter (Figure 7A) and complete absence of fibrils. Whereas the border appeared darker (more electron-dense) at the previous time point due to an inhomogeneous distribution of electron-dense particles constituting this area, the border was now formed by an accumulation of fibrils from the casein matrix (Figure 7B and E). It is worthwhile noting that the emulsion layer surrounding the fat globules had not changed greatly in appearance, that is, the emulsion layer was still very thin (Figure $7 \mathrm{C}$, arrowheads). However, occasionally a few fibrils were seen in contact with this layer (Figure 7D, arrowhead).

TEM of Samples Taken at 275 Minutes. After 275 min of processing, the viscosity was at the beginning of the second phase; the protein separation was more pronounced, reflective of fundamental changes throughout the casein matrix. The fibrils, now clearly visible as long tube-like structures with an electrondense ring around a central electron-opaque cavity, were observed at times in large bundles with many of the individual fibrils regularly aligned. Smaller fat globules often were completely surrounded by several bundles of fibrils that had abutted at different angles (Figure 8C). Fibrils were frequently seen attached to fat globules either via their transverse (Figure $8 \mathrm{~F}$ ) or their longitudinal surface (Figure 8G), which then gave the appearance of brush bristles because of the parallel alignment of the fibrils.
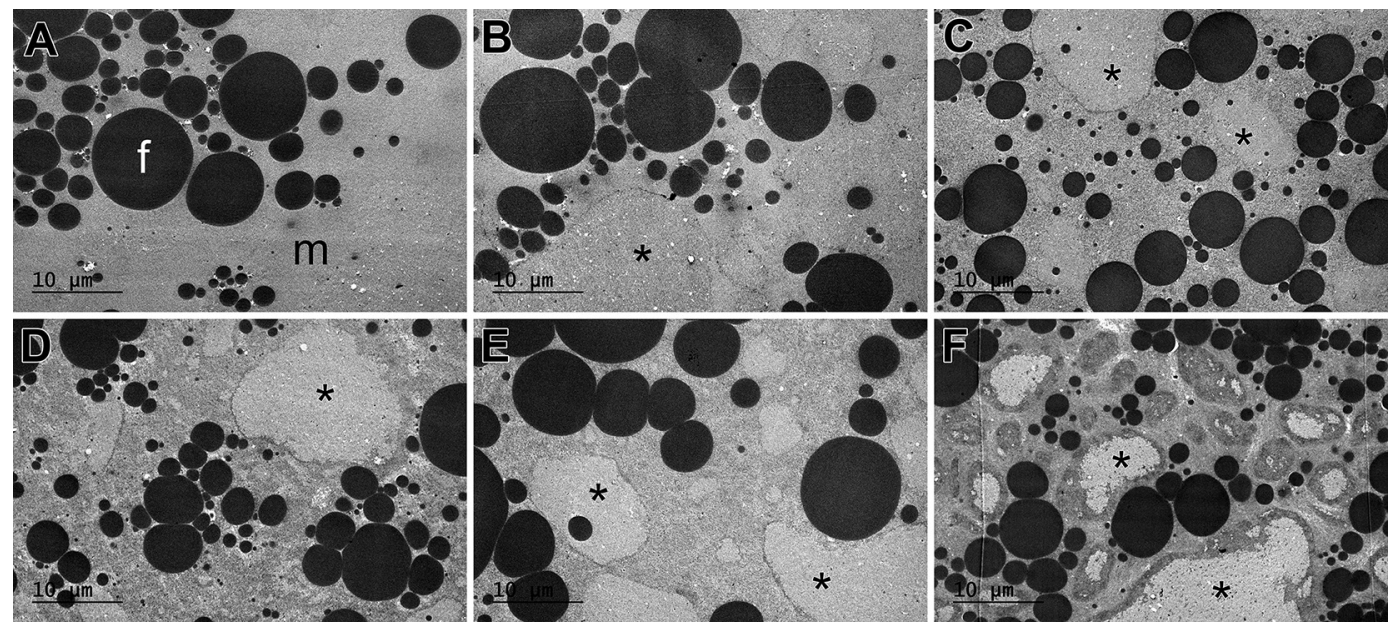

Figure 4. Low-magnification transmission electron micrographs of model processed cheese showing a progressive separation of the protein matrix during processing into areas with different electron densities (asterisks). (A) 15 min, (B) 50 min, (C) 175 min, (D) 275 min, (E) 315 min, (F) $410 \mathrm{~min} ; \mathrm{f}=\mathrm{fat} ; \mathrm{m}=$ casein matrix. Instrumental magnification at 500×, with the scale bar representing $10 \mu \mathrm{m}$. 
TEM of Samples Taken at 315 Minutes. The fibril bundles so conspicuously noticeable after $275 \mathrm{~min}$ of processing had, by qualitative assessment, reduced in size and frequency 40 min later amid individual fibrils extending at various angles (Figure 9). This coincided with the second and more rapid increase in the apparent viscosity. The constant shearing effect was also visible at the fat globule surface with parallel arrays of attached fibrils now showing a more convoluted orientation (Figure 9D). The extent and morphology of the newly separated protein areas of low electron density appeared comparable to that seen at the previous time point (Figure $9 \mathrm{~A}$ and $\mathrm{B}$ ).

TEM of Samples Taken at 410 Minutes. At the last time point investigated - and highest apparent viscosity measured (of the 6 samples, but not over the entire time course due to clumping of the molten mass) - several striking morphological changes were recorded. The separation of the protein matrix had further progressed with the appearance of a thick sheath around the newly formed areas (Figure 10A, asterisks). Emulsified fat globules, particularly smaller ones, appeared to have been pushed alongside the presumably less mobile new areas through the casein matrix (Figure 10B). Remarkable changes were seen in the casein matrix with fibril bundles all but gone. Instead, fibrils seemed shorter and irregularly distributed (Figure 10C). The thick sheath around the newly formed areas, when investigated at higher magnification, was filled with randomly oriented fibril fragments and very fine needle-like structures (Figure 10D, arrowheads).

\section{Evaporational Moisture Losses During the Creaming Reaction}

Repeated observations of visible traces of condensation on the inside of the 2 lid halves of the custom-made geometry, especially after long runs, prompted us to quantify the DM content of the sample also after each run was completed. Results indicate that moisture losses were significant within the first 50 min in which the DM increased by $3.45 \%$ (Supplemental Figure S1A, https:// doi.org/10.6084/m9.figshare.14583225.v1). Considering time points past $50 \mathrm{~min}$, however, the dry matter of the processed cheese samples was approximately constant at $44.21 \pm 0.81 \%$. Thus, fibril formation observed in the later stages of processing would appear to have been largely unaffected by changes in the moisture content. $\mathrm{pH}$ values did not change significantly over the entire
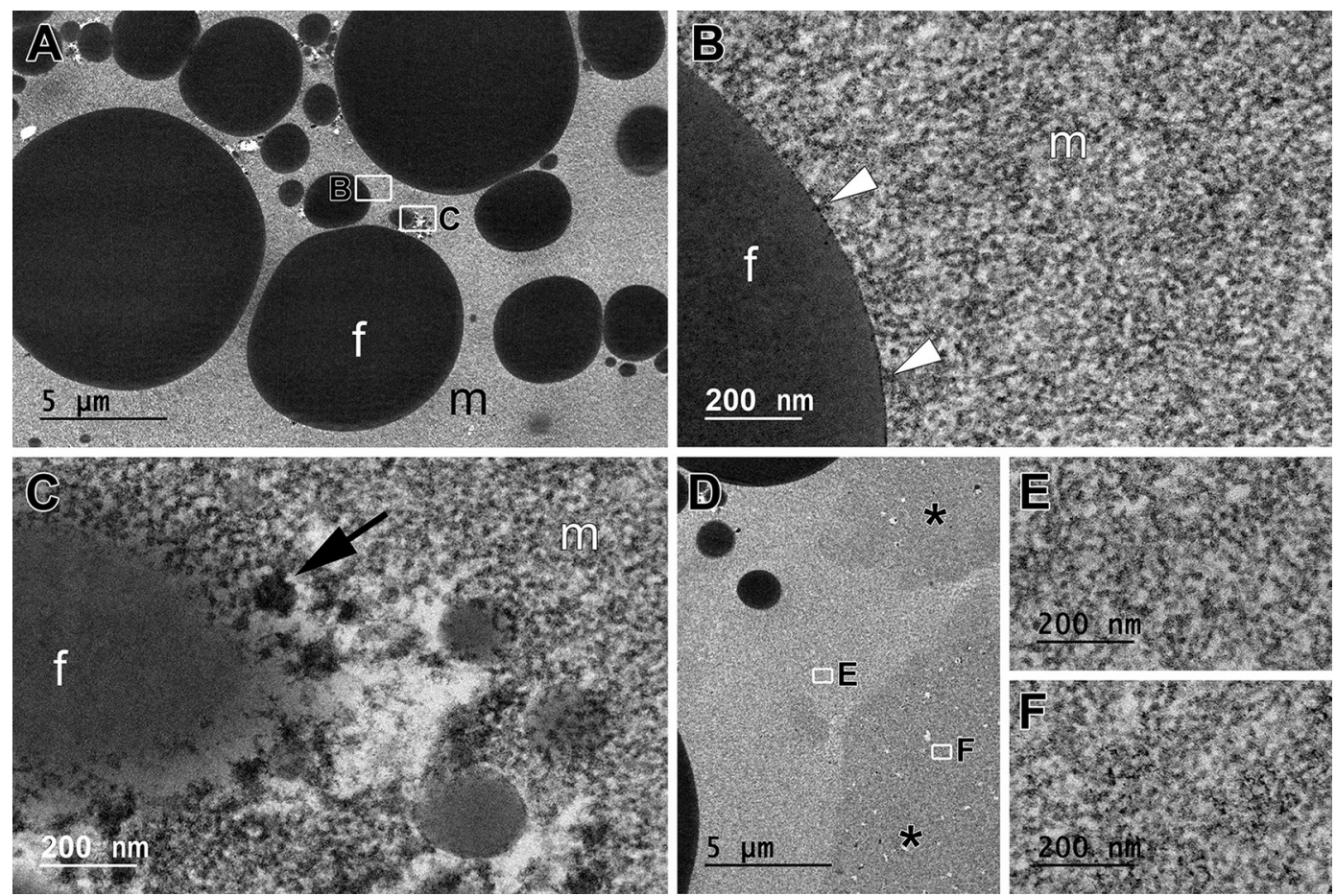

Figure 5. Transmission electron micrographs of model processed cheese after 15 min of processing time. (A) Fat globule clustering and homogeneous casein matrix distribution. (B) Fat globule-casein matrix interface with arrowheads pointing to a thin protein layer formed by the casein matrix around the fat globule and thereby emulsifying it. (C) Areas of undissociated micellar casein concentrate adjacent to a fat globule (arrow). (D) Casein matrix with some areas of higher electron density (asterisks). (E) Detail of the casein matrix. (F) Detail of the area of higher electron density; $\mathrm{f}=$ fat; $\mathrm{m}=$ casein matrix. White boxes are enlarged in the respective panels as indicated by the adjacent letters. 

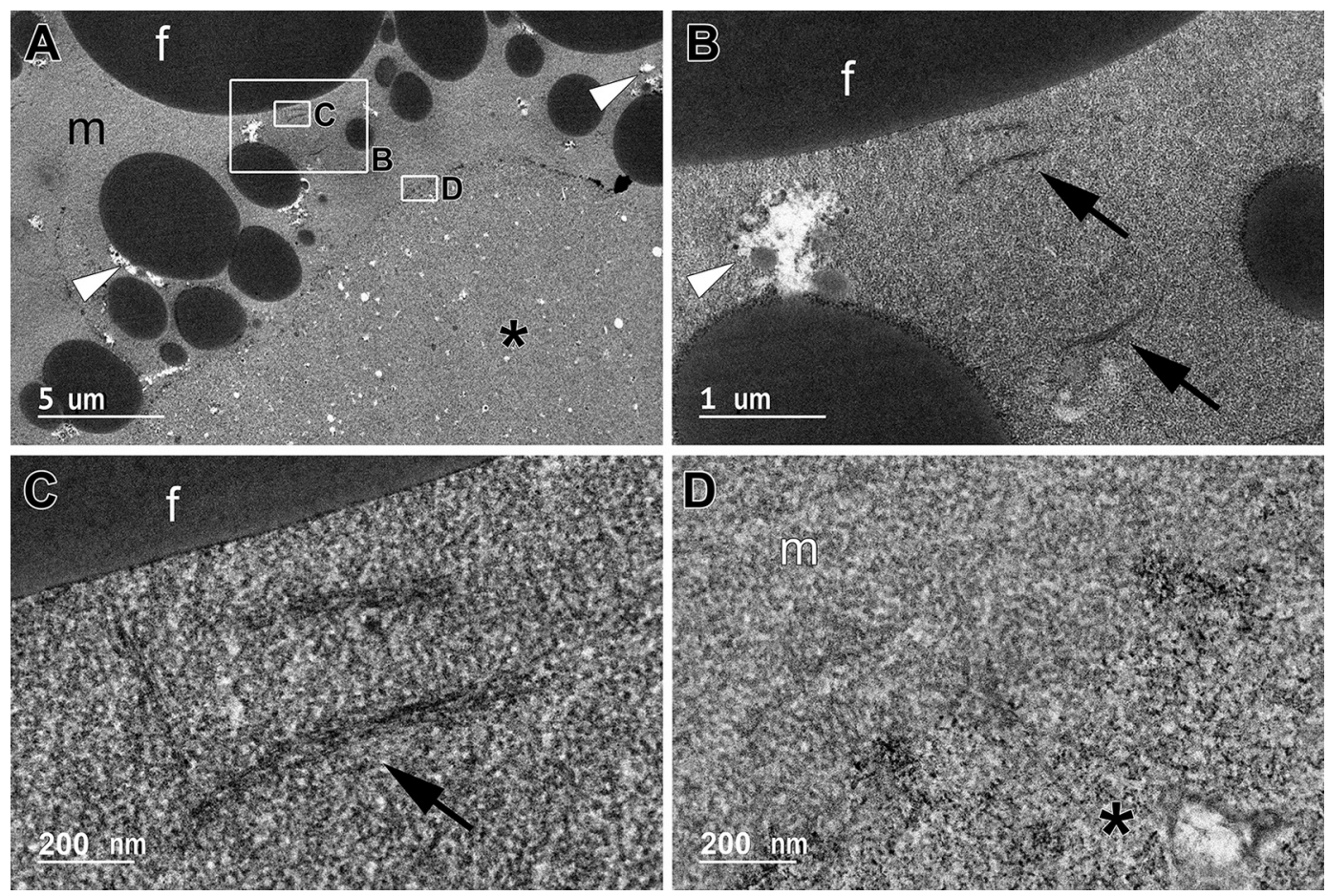

Figure 6. Transmission electron micrographs of model processed cheese after 50 min of processing time: Beginning separation of the protein matrix and appearance of fibril-like structures. (A) Fat globule clustering and early protein separation of the casein matrix. (B) Appearance of fibril-like structures (arrows) in the casein matrix. (C) Detail of the fibril-like structure (arrow) in the casein matrix. (D) Detail of the casein matrix with protein separation; $\mathrm{f}=$ fat; $\mathrm{m}=$ casein matrix. The arrowheads in $\mathrm{A}$ and $\mathrm{B}$ point to areas of partially dissociated micellar casein concentrate similar to that seen at the previous time point. Asterisks in A and D mark distinctly different areas within the casein matrix. White boxes are enlarged in the respective panels as indicated by the adjacent letters.

processing time (Supplemental Figure S1B, https://doi .org/10.6084/m9.figshare.14583225.v1).

\section{DISCUSSION}

Key elements of the structural changes observed by LM and TEM during the creaming reaction in our processed cheese model system are (1) a change in size, number, and distribution of fat globules, (2) a progressive separation of the casein matrix into fibrillogenic and nonfibrillogenic fractions, (3) formation and higher-order structuring of fibrils and their partial degradation in the casein matrix, and (4) increasing interaction of the fibrils with the fat globule surface leading to a higher degree of emulsification.

\section{Fat Globule Size, Number, and Distribution}

The role of fat in regard to the creaming reaction in processed cheese has been debated by various investigators without a clear consensus. Some have argued that fat is essential for creaming to take place (Berger et al., 1998), whereas others have put forward the idea that creaming is predominantly caused through protein-protein interactions (Lee et al., 2003). When a fat source was included in the formulation, however, similar observations were made: fat globules initially displayed a broad size range and were unevenly distributed throughout the casein matrix but decreased in size over time while also increasing in number, with the fat distribution more even at later stages of processing (Rayan et al., 1980; Lenze et al., 2019). The degree of emulsification, as indicated by the formation of a finely dispersed fat phase, was reasoned to contribute to the viscosity increase (Lenze et al., 2019). If one assumes an even layer of protein around fat globules, a larger number of smaller fat globules, as seen toward the end of processing, would result in more sites on the surface of fat globules being accessible for an interaction with the protein phase with a resultant increase in viscosity. This also applied to results from our study.

It is worth noting that the decrease in fat globule size was not gradual during the processing time in our experiments. Rather, fat globule size appeared similar even well into the time period. Only after $275 \mathrm{~min}$ of processing was a clear size reduction evident. From this observation it can be concluded that the effect of the fat phase on the viscosity curve was negligible in the first half but likely strong throughout the second half of the creaming reaction and thus contributed to the 
second rapid increase of the viscosity profile presented in Figure 2.

\section{Progressive Separation of the Casein Matrix}

The separation of the casein matrix into areas of different electron density and morphology is another key element in the structure formation process. Although it is difficult at this point to suggest the nature of these newly formed regions, they clearly originated from the casein matrix. Based on the observed morphology and electron density pattern, they must be also of proteinaceous material. Neither calcium, phosphate, nor citrate species have enough contrast to be visible in bright-field TEM unless they form large insoluble crystals. Crystals derived from melting salts and from minerals in natural cheese have been documented for processed cheese, and in fact are considered a defect (Kapoor and Metzger, 2008). Their unique morphology, or what is left of them within the casein matrix after sample processing for TEM, makes them easily recognizable (Caric et al., 1985).

As MCC ( $\sim 98 \%$ casein and $\sim 2 \%$ whey proteins) was the only protein source used in our experiments, it can be deduced that the distinctive areas were formed by one or more of the four different casein fractions derived from the casein micelle $\left(\alpha_{\mathrm{S1}^{-}}, \alpha_{\mathrm{S2}^{-}}, \beta-\right.$, and $\left.\kappa-\mathrm{CN}\right)$. The TEM results suggest at least two distinct protein species, or fragments. Whey proteins are unlikely to have participated in the structure formation, based on approximated area ratios of the newly formed areas compared with the casein matrix; that is, a whey protein concentration of $\sim 2 \%$ is not a sufficient quantity to form such large areas.

Although evidence of the separation of the casein matrix was noticed during the entire time period, the newly formed areas were particularly conspicuous at the very end, with a broad sheath encircling them. At this point, it can also only be speculated that the fine needle-like structures that were seen within this sheath are degradation products of fibrils found mixed with the needles.

In conclusion, it is likely that the separation of the casein matrix into distinct areas of some yet unidentified but amorphously aggregated casein species contributed to the increase in viscosity mostly throughout the second half, and particularly at the end of the time course.
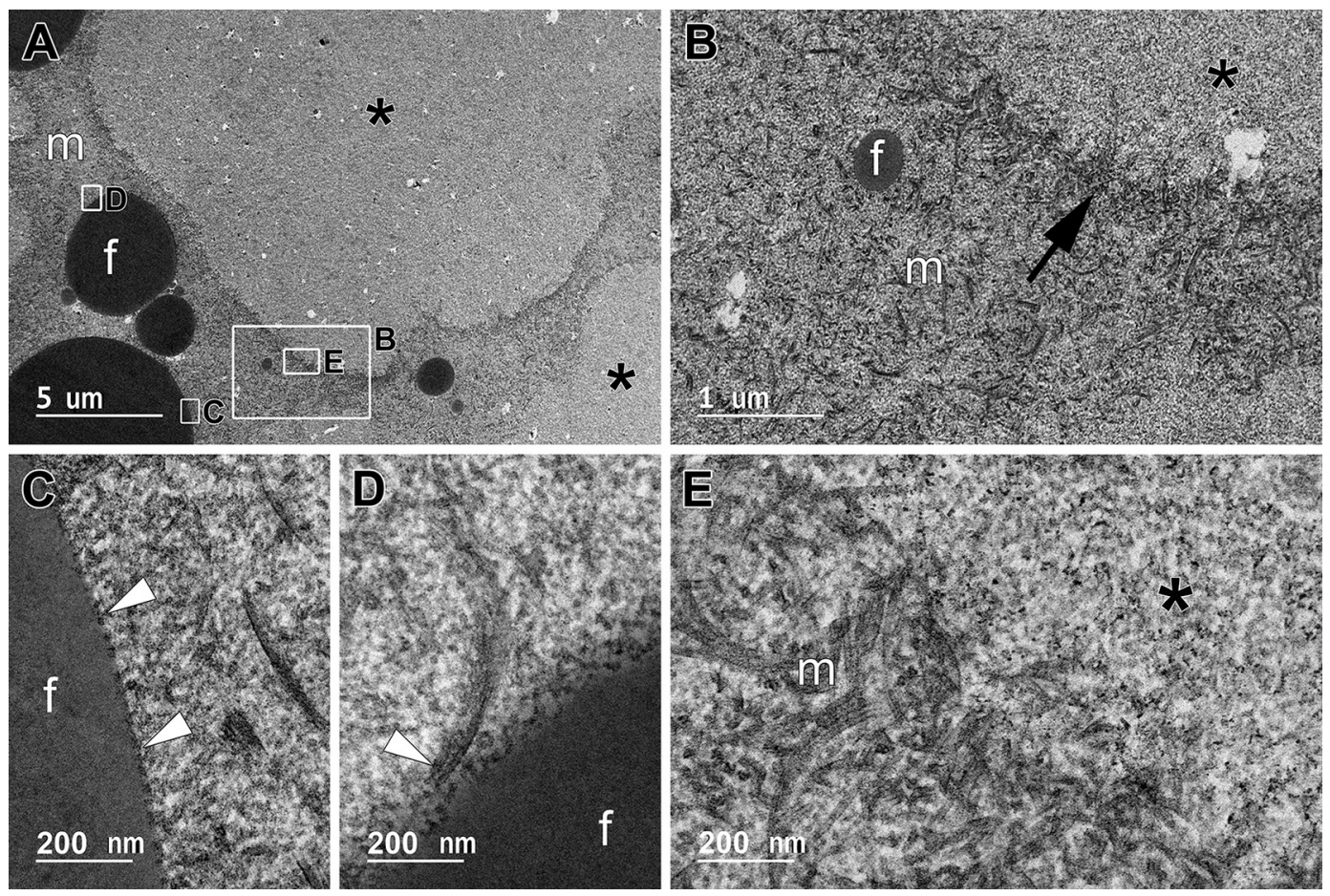

Figure 7. Transmission electron micrographs of model processed cheese after 175 min of processing time: Protein matrix separation and extension of fibrils. (A) Clear separation of the casein matrix into areas of high and low electron density. (B) High density of fibrils at the interface of the casein matrix and separated areas (arrow). (C) Detail of the casein matrix with fibrils and evenly emulsified fat globule (arrowheads). (D) Detail of the casein matrix with fibrils attaching to the fat globule (arrowhead). (E) Detail of the casein matrix at the interface; $\mathrm{f}=$ fat; $\mathrm{m}=$ casein matrix. Asterisks in A, B, and E mark the protein area characterized by low electron density. White boxes are enlarged in the respective panels as indicated by the adjacent letters. 

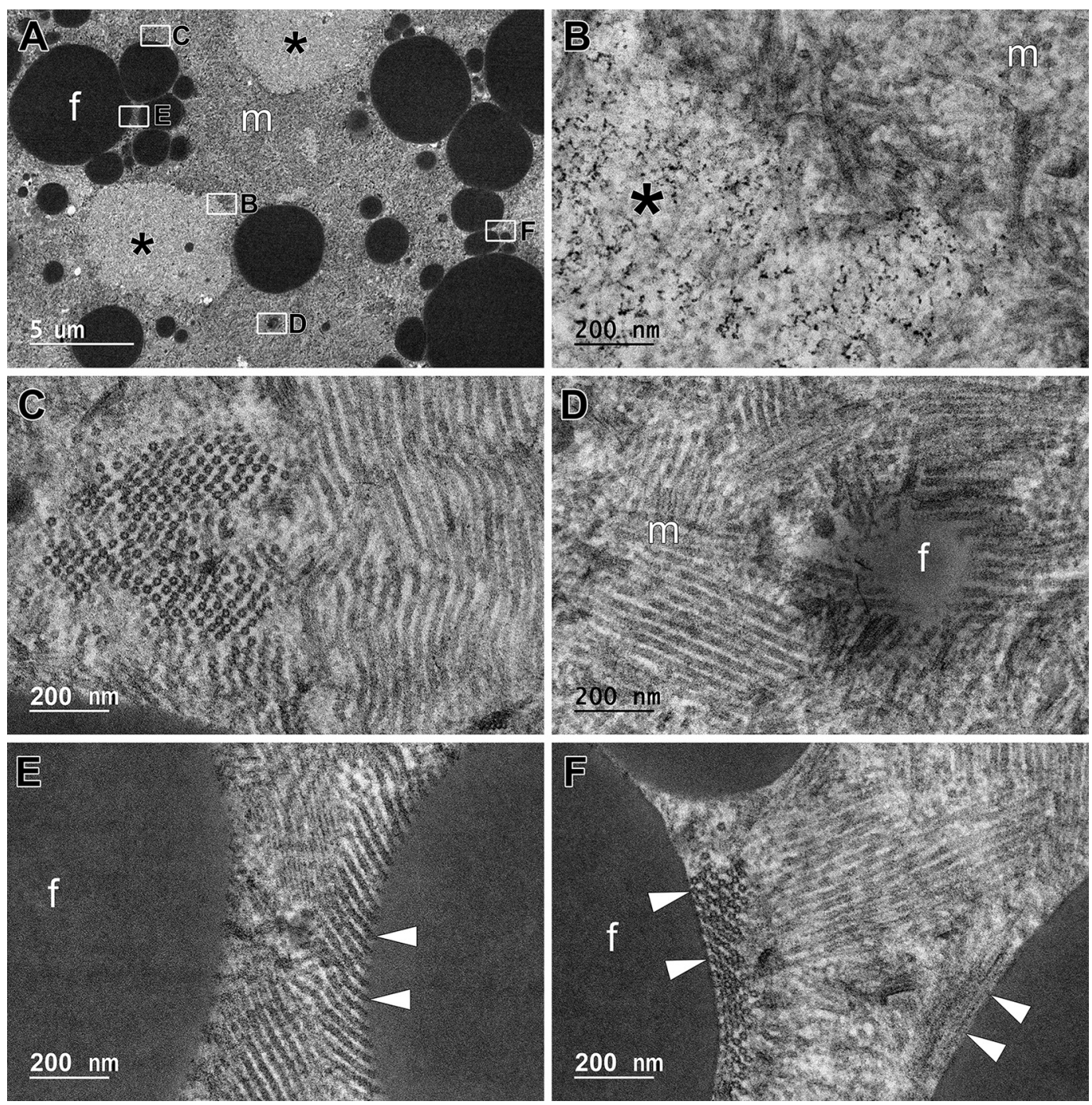

Figure 8. Transmission electron micrographs of model processed cheese after 275 min of processing time: Protein matrix separation and casein fibril alignment in bundles. (A) Clear protein separation of the casein matrix into areas of high and low electron density. (B) High density of fibrils at the interface. (C) Detail of the casein matrix with large bundles of highly ordered fibrils in cross (left) and longitudinal (right) section. (D) Bundles of fibrils completely surrounding a small fat globule. (E) and (F) Two large fat globules with fibrils attached to their surface. The arrowheads point to fibrils attached via their transverse side $(\mathrm{E})$ and their longitudinal side $(\mathrm{F}) ; \mathrm{f}=\mathrm{fat} ; \mathrm{m}=\mathrm{casein}$ matrix. Asterisks in (A) and (B) mark the protein area of low electron density. White boxes are enlarged in the respective panels as indicated by the adjacent letters.

\section{Casein Fibrils}

It is even more difficult to suggest the exact nature of the fibrils and their genesis. What is clear, however, is that they derived from micellar casein concentrate that, under the influence of the melting salts, initially formed a mostly homogeneous granular casein matrix. Because fibril-like structures started to appear only after the separation of the protein matrix became evident, it is tempting to speculate that these features are functionally linked and that the calcium-sequestration of the melting salts not only led to a general dissociation of the casein matrix, as commonly assumed, but more specifically drove the segregation of casein proteins into species that were able to form fibrils while others, that were not able to form fibrils, aggregated in different areas. It is conceivable that the loss of calcium ions from the casein matrix increasingly destabilized the protein structure by unmasking previously hidden hydrophobic areas that were then able to form new structures. And as such, the protein separation might be considered a prerequisite for the subsequent fibril formation in our system.

Fibril formation has been demonstrated for native and reduced forms of $\kappa$-CN (Farrell et al., 2003; Thorn et al., 2005, 2008; Lee et al., 2019), $\alpha_{\mathrm{S}_{2}} \mathrm{CN}$ (Thorn et 

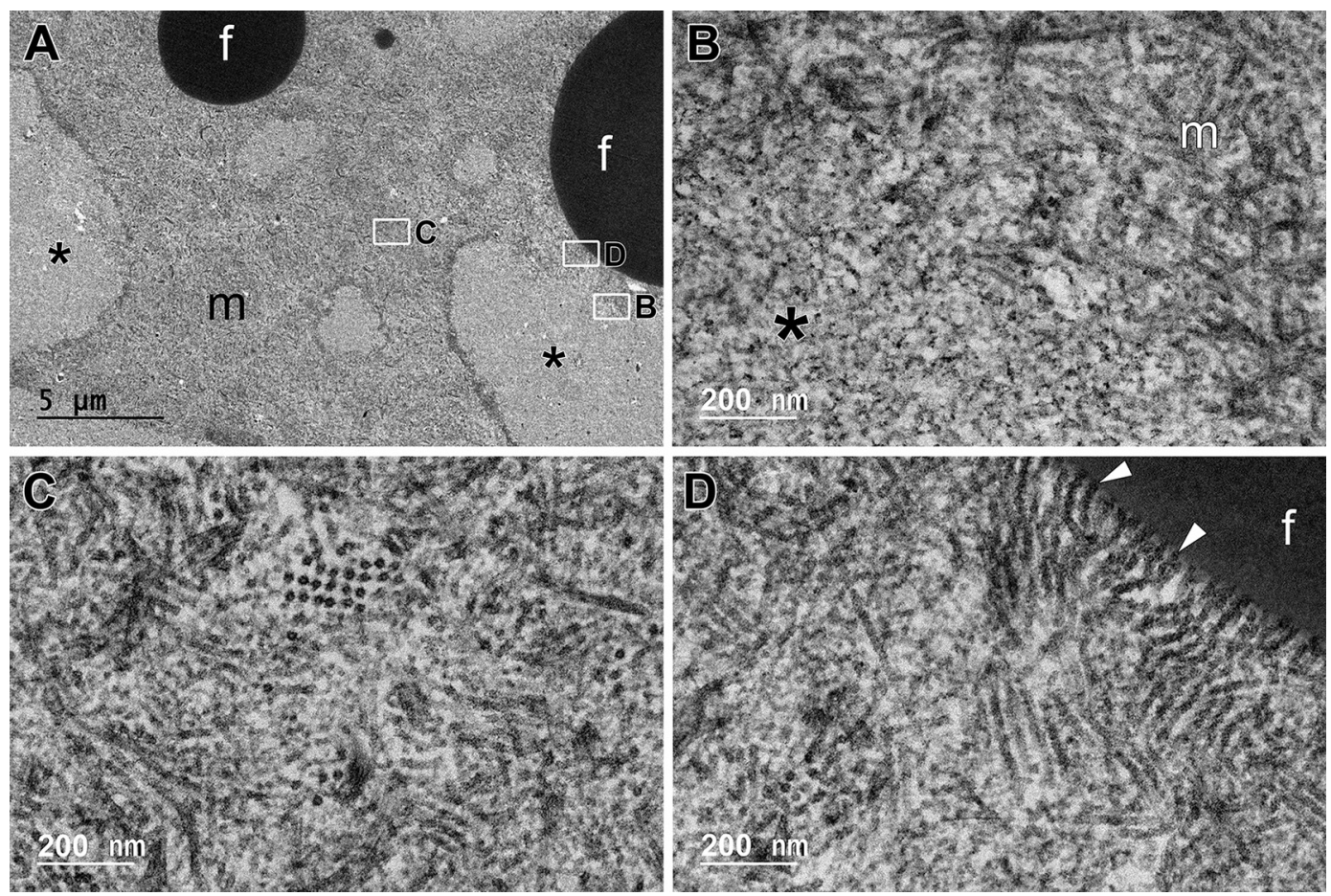

Figure 9. Transmission electron micrographs of model processed cheese after 315 min of processing time: Protein matrix separation and breakdown of casein fibril bundles. (A) Clear protein separation of the casein matrix into areas of high and low electron density. (B) High density of fibrils at the interface. (C) Detail of the casein matrix with fibril bundles reduced in size. (D) Convoluted fibrils at the surface of a fat globule (arrows); $\mathrm{f}=$ fat; $\mathrm{m}=$ casein matrix. Asterisks in (A) and (B) mark the protein areas of low electron density. White boxes are enlarged in the respective panels as indicated by the adjacent letters.

al., 2008), and, to some degree, $\beta$-CN, although not under physiological conditions (Pan and Zhong, 2015). Fibril formation could not be induced for $\alpha_{\mathrm{S}_{1}} \mathrm{CN}$ (Thorn et al., 2008). On the contrary, $\alpha_{\mathrm{S} 1}-\mathrm{CN}$ and $\beta-\mathrm{CN}$ have been shown to suppress fibril formation when mixed with fractions of $\kappa-\mathrm{CN}$ or $\alpha_{\mathrm{S}_{2}} \mathrm{CN}$ (Thorn et al., 2008; Treweek et al., 2011) reflective of their putative role as molecular chaperones in the prevention of amyloidosis in casein micelle secreting cells and their surrounding tissues of the lactating cow (Holt et al., 2013). As these studies were conducted with single casein fractions (often chemically highly modified), or binary combinations at the most, it remains to be determined how these results can be applied to the creaming reaction in processed cheese.

Interestingly, there are a few older studies and one recent study reporting on fibril-like structures found not in isolated fractions, but more importantly, in the casein matrix of processed cheese (Kimura and Taneya, 1975; Taneya et al., 1980; Heertje et al., 1981; Tamime et al., 1990; Fu et al., 2018). Using the same thinsectioning technique after chemical fixation, Taneya et al. (1980) observed faint network-like structures of longer protein strands within the casein matrix of hardtype processed cheese, that is, processed cheese that was made with $2.2 \%$ polyphosphate as the melting salt. No such structures were evident when a melting salt mixture was used consisting of $1.0 \%$ sodium citrate and $1.5 \%$ polyphosphate. It appeared that the formation of these particular structures primarily depended on the type of the melting salt. Fu et al. (2018) confirmed this conclusion when they also reported on some finestranded structures in the protein matrix of processed cheese with their presence or absence determined by the composition of the melting salts. The absence of any string-like structures in the protein phase of processed cheese made only with sodium phosphate (the exact amount was not given) is also evident in TEM images published by Kimura and Taneya (1975). More pronounced string-like protein structures with a diameter of $10 \mathrm{~nm}$ and an approximate length of 300 nm were documented by Heertje et al. (1981) in their study on the microstructure of processed cheese. Although the composition of the melting salts was not clearly stated, the fact that protein strands were seen dictates that some combination of polyphosphates was used. The authors also recorded the torque exerted on the stirrer, and although the apparent viscosity profile was not identical to that presented here, it shares the general feature of a viscosity increase over time. The 

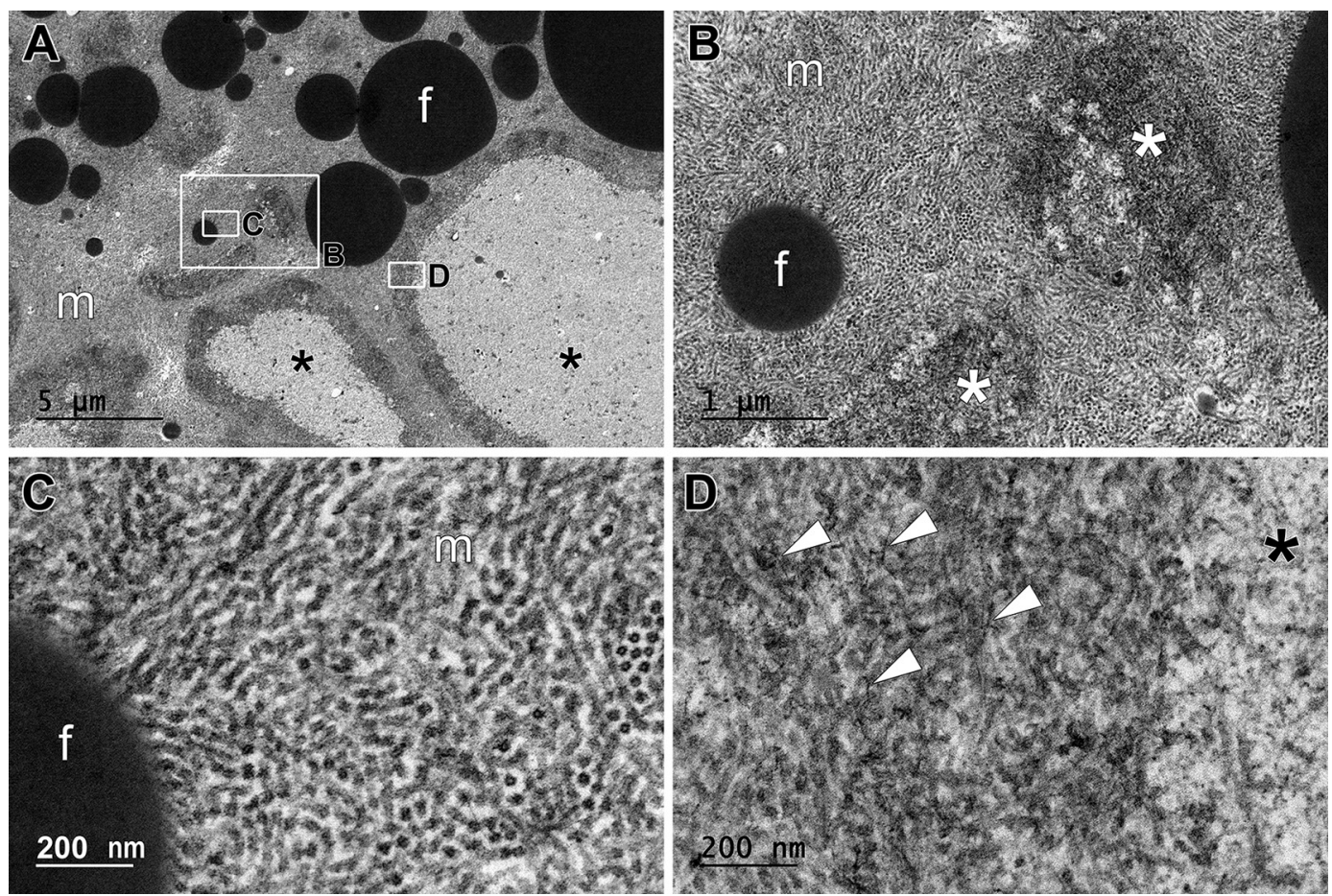

Figure 10. Transmission electron micrographs of model processed cheese after 410 min of processing time: Protein matrix separation and fragmentation of casein fibrils. (A) Protein separation of the casein matrix with a pronounced electron-dense band surrounding the newly formed areas. (B) A small fat globule in a channel of fragmented casein fibrils. (C) Detail of the casein matrix with shorter and mostly irregularly packed fibrils. (D) Short fibrils and very fine needles (arrowheads) within the electron-dense band; $\mathrm{f}=$ fat; $\mathrm{m}=$ casein matrix. Asterisks in (A), (B), and (D) mark the protein areas of low electron density. White boxes are enlarged in the respective panels as indicated by the adjacent letters.

increase in viscosity was related to the presence of a few irregular fine strands, which were seen at peak viscosity as thicker, straight fibrils in random orientation throughout the entire protein matrix; a parallel strand alignment, as the authors stated, cannot be discerned on the basis of the published micrographs. The fibrils did not persist throughout the remainder of the time course; rather, the proteins coagulated and formed compact aggregates. Although not the focus of the study (the informative micrograph depicting the fibrils was included in the discussion with the reviewers, printed subsequently to the main article), Tamime et al. (1990) provided yet another example of fibril formation in the protein matrix of processed cheese, although the fibrils were hard to distinguish from the background due to the presence of a multitude of small electron-dense particles assumed to be staining artifacts.

There seems to be a common theme in all these studies, with the demonstration of new protein structures in the casein matrix assumed to be related to the viscosity increase during the creaming reaction. However, none show the structures with the same clarity as presented here. Moreover, although these structures were generally described as fibril-like, we show evidence of a more regular structure in the form of hollow tubes with the additional complexity of higher-order alignment of said tubes into bundles. It is important to note that the structures in our study were observed first in the casein matrix and were only at later time points found attached to fat globules. This clearly indicates the importance of protein-protein interactions as the primary driver of the viscosity change.

\section{Interaction of Casein Fibrils with Fat Globules and Degree of Emulsification}

Under the influence of the melting salts, the casein micelles in the concentrated powder quickly dissociated into a homogeneous casein matrix, which rapidly adsorbed to the oil-water interface, thereby producing a stable layer protecting fat globules from coalescing. After casein fibrils formed within the casein matrix, they were soon also seen attached to the surface of the fat globule. With the elongation of the fibrils and higher-order structuring, the frequency and extent of those contacts had strongly increased to the point that some fat globules appeared tethered to one another by means of an ordered array of fibrils. It is very conceivable that this tethering increased the viscosity locally. Coupled with the fact that the mixture was under slow 
but constant agitation, it is easy to imagine how those areas would experience a higher degree of strain and, as a consequence of this continued milling or shearing, larger fat droplets were reduced in size, whereas the total number of fat globules increased at the same time. A fine emulsion had formed.

Interestingly, the fibrils were seen attached to the fat globules not only via their transverse, but also via their longitudinal side, which implies that they were reactive, or "sticky," across their entire surface. When organized in bundles within the casein matrix, the fibrils also abutted at various angles to each other, confirming this conclusion. This reactivity along the entire surface area is yet another plausible mechanism by which the viscosity increased, in particular toward the end of the time period, when the fibrils started to break down with many smaller fibril fragments seen to fully occupy the casein matrix.

Although a previous study indicated a migration of the casein proteins from the fat globule surface to the matrix at the end of the creaming reaction (Lenze et al., 2019), no sign of desorption was seen in this study. On the contrary, the degree of emulsification appeared only to intensify over the course of time. A reason for this discrepancy may be found in the slightly different experimental set up.

\section{Different Key Elements Act in Concert to Bring About the Structure Formation in Processed Cheese}

It becomes obvious from the discussion above that the mechanisms underlying the structure formation during the so-called creaming reaction are both very complex and dynamic. Figure 11, which is based on the interpretation and qualitative assessment of various features from more than 1,800 micrographs taken during the course of this study, gives a summary of the key elements related to the viscosity change in our processed cheese model system, their initial occurrence and relative duration.

In our opinion, the formation of proteinaceous fibrils lies at the heart of the creaming reaction, which is better described as a texturization process, as highlighted in an updated model (Figure 12), and was set in motion by the segregation of the casein matrix into proteins that could form fibrils under the conditions of our experiments and others that could not. This is assumed to be a direct consequence of the calcium-sequestering ability of the used melting salts. With the development of the fibrils, their higher-order structuring and increased interaction with fat globules, the viscosity of the molten cheese mass increased while a finer emulsion was formed. Fat globules were therefore not necessary for the creaming reaction to take place but had an ad- ditional effect on the viscosity increase. This is in agreement with the conclusions from the study by Lee et al. (2003), which state that protein-protein interactions were the main driver of the viscosity increase, whereas the fat phase was speculated to act as a modulator. That fat modified the viscosity curve was also shown by Lenze et al. (2019) when they varied the fat levels of the formulation. Of note is the fact that in a totally fat-free formulation, a small yet recognizable viscosity increase was still recorded by Lenze et al. (2019), which we would also expect based on our findings of the extensive protein-protein interactions.

\section{Practical Applications for the Processed Cheese Industry}

Controlling this complex and dynamic structure formation is particularly important for downstream units, including the buffer tank for the hot product

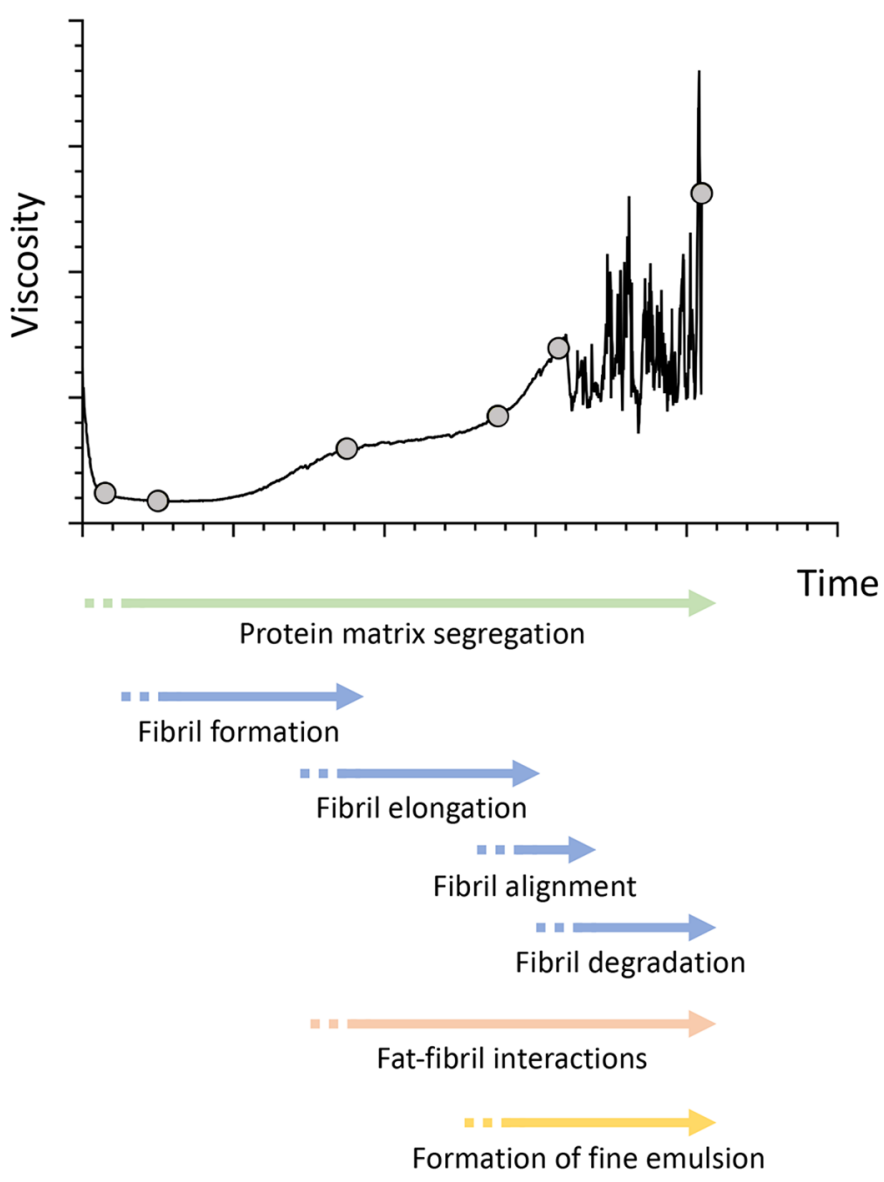

Figure 11. Key elements and their development during the "creaming reaction" in a processed cheese model system. The arrows below the characteristic viscosity profile indicate initial occurrence and relative duration of each element. Different colors are used to distinguish the individual elements. 


\section{Non-fibrillogenic caseins}

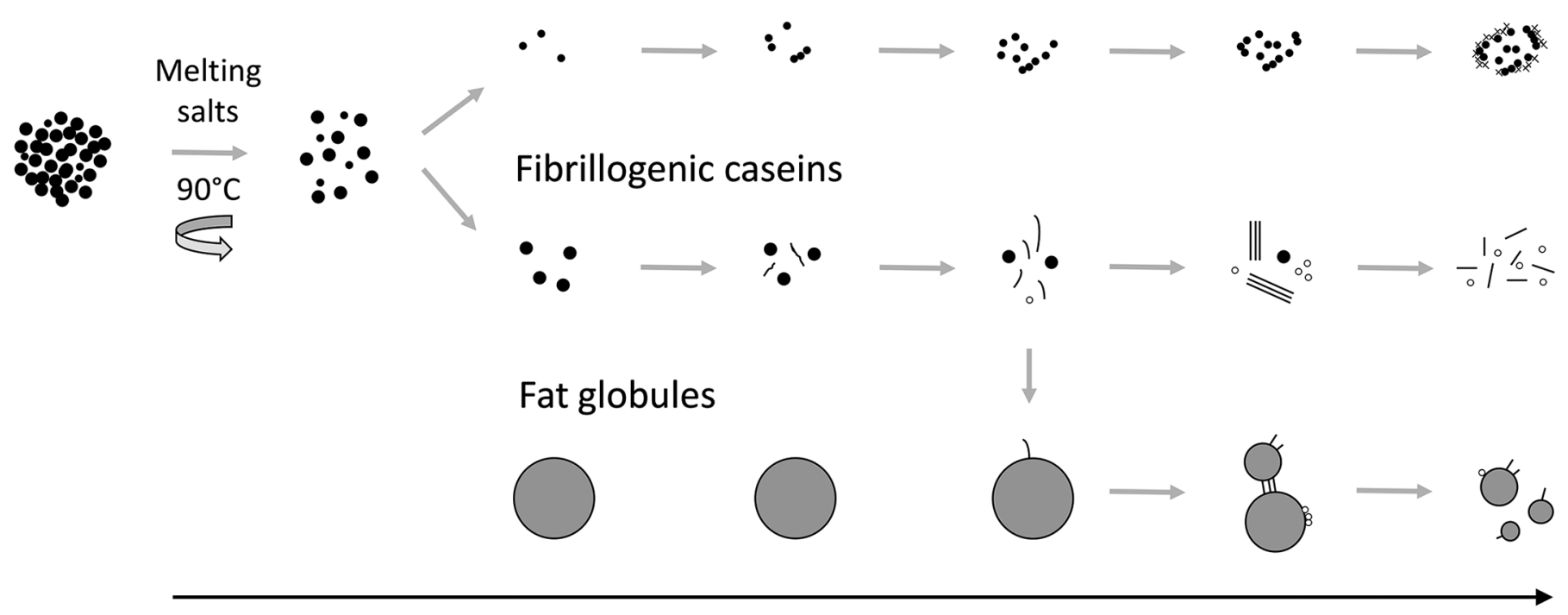

Reaction Time (high temperature, constant stirring)

Figure 12. An updated processed cheese texturization ("creaming") model. Casein proteins (closed circles) dissociate under the influence of the melting salts combined with heat and stirring into fibrillogenic and nonfibrillogenic fractions. With time, the fibrils (lines and open circles) first elongate, align into bundles, and then partially fragment. Increasing contact of fibrils with fat globules (large, gray circles) combined with shear forces eventually leads to a fine emulsion. Protein separation, fibril formation, and development of a fine emulsion all contribute to an increase in the apparent viscosity of the system.

located between cooker and filler. If fill levels and thus residence times vary due to, for example, production delays, the structure of the molten mass will continuously change in accordance with the creaming reaction. Stirring speed could be used to influence the reaction speed. In such a case, the filler feed tank would be considered a continuous stirred tank reactor mixing newly arriving processed cheese with already existing product volumes, thus accelerating the structure formation as seeding material in the formation of fibrillar proteinaceous structures. If process design and operations are performed without taking these factors into consideration, the structure formation would proceed in an uncontrolled manner, leading to detrimental product variability.

\section{Proposed Change in Terminology from "Creaming" to "Texturization"}

Although the term "creaming reaction" or "creaming effect" has a clear meaning within the processed cheese industry, it can be misleading, as it may be confused with another process more commonly known as "creaming"; that is, the migration of fat droplets in unhomogenized milk through the continuous phase, leading first to emulsion destabilization and then to an oil-water phase separation. To avoid confusion, we propose the use of the term "texturization" instead of "creaming" when referring to the viscosity increase during processed cheese manufacture.

\section{CONCLUSIONS}

Our extensive study on the structure formation during the creaming (or texturization) reaction in a processed cheese model system showed that several different key elements were involved and acted both in parallel and also sequentially, to bring about the typical viscosity profile; namely, a progressive separation of the casein matrix into fibrillogenic and nonfibrillogenic areas, de novo fibril formation and higher-order structuring into bundles, partial breakdown of fibrils, and unique interaction of fibrils with fat globule surfaces, leading to a finer emulsion. Although protein-fat interactions were important during the later stages of the structure formation, protein-protein interactions were the primary driver. New scientific insights gained from this study not only fit well with previous observations but substantially extend our understanding of this peculiar reaction. This knowledge could be directly applied to design and optimization of processed cheese manufacturing lines to better control and standardize the processing conditions during and after the cooking step, thereby reducing product variability. 


\section{ACKNOWLEDGMENTS}

We acknowledge Stefanie Sedlmeier for preparing processed cheese samples in the rheometer. Electron microscopy was performed at the Health Sciences EM Core at the University of Utah, Salt Lake City. Technical assistance of Nancy Chandler (University of Utah) and technical advice of Mark KirkPatrick (Jeol USA) is gratefully acknowledged. Our thanks go to Don McMahon (Utah State University) for valuable discussions during the writing of the manuscript, and to Kandy Baumgardner (Utah State University) for proofreading. Project funding was available through Deutsche Forschungsgemeinschaft (DFG; German Research Foundation), project \# 315464976, and through the Western Dairy Center at Utah State University. The authors declare no conflict of interest.

\section{REFERENCES}

Berger, W., H. Klostermeyer, K. Merkenich, and G. Uhlmann. 1998. Processed Cheese Manufacture: A JOHA Guide. BK Giulini Chemie.

Bozzola, J. J., and L. D. Russell. 1999. Electron Microscopy Principles and Techniques for Biologists. 2nd ed. Jones and Bartlett Publishers.

Caric, M., M. Gantar, and M. Kalab. 1985. Effects of emulsifying agents on the microstructure and other characteristics of process cheese: A review. Food Microstruct. 4:297-312.

Dumpler, J. 2018. Heat Stability of Concentrated Milk Systems: Kinetics of the Dissociation and Aggregation in High Heated Concentrated Milk Systems. Springer Spektrum.

Dumpler, J., H. Wohlschläeger, and U. Kulozik. 2017. Dissociation and coagulation of caseins and whey proteins in concentrated skim milk heated by direct steam injection. Dairy Sci. Technol. 96:807826. https://doi.org/10.1007/s13594-016-0304-3.

Farrell, H. M. Jr., P. H. Cooke, E. D. Wickham, E. G. Piotrowski, and P. D. Hoagland. 2003. Environmental influences on bovine k-casein: reduction and conversion to fibrillar (amyloid) structures. J. Protein Chem. 22:259-273. https://doi.org/10.1023/A: 1025020503769 .

Fu, W., Y. Watanabe, H. Satoh, K. Inoue, N. Moriguchi, K. Fusa, Y. Yanagisawa, T. Mutoh, and T. Nakamura. 2018. Effects of emulsifying conditions on creaming effect, mechanical properties and microstructure of process cheese using a rapid visco-analyzer. Biosci. Biotechnol. Biochem. 82:476-483. https://doi.org/10.1080/ 09168451.2018.1431106.

Guinee, T. P., M. Carić, and M. Kaláb. 2004. Pasteurized processed cheese and substitute/imitation cheese products. Pages 349-394 in Cheese: Chemistry, Physics and Microbiology. Vol 2: Major Cheese Groups. 3rd ed. P. F. Fox, P. L. H. McSweeney, T. M. Cogan, and T. P. Guinee, ed. Elsevier Academic Press.

Heertje, I. 1993. Structure and function of food products: A review. Food Struct. 12:343-364. https://doi.org/10.1016/j.foostr.2013.06 .001 .

Heertje, I., M. J. Boskamp, F. van Kleef, and F. H. Gortemaker. 1981. The microstructure of processed cheese. Neth. Milk Dairy J. 35:117-179.

Holt, C., J. A. Carver, H. Ecroyd, and D. C. Thorn. 2013. Caseins and the casein micelle: Their biological functions, structures, and behavior in foods. J. Dairy Sci. 96:6127-6146. https://doi.org/10 .3168/jds.2013-6831.

Kalab, M., J. Yun, and S. H. Yiu. 1987. Textural properties and microstructure of process cheese food rework. Food Microstruct. $6: 181-192$

Kapoor, R., and L. E. Metzger. 2008. Process cheese: Scientific and technological aspects - A review. Compr. Rev. Food Sci. Food Saf. 7:194-214. https://doi.org/10.1111/j.1541-4337.2008.00040.x.

Kimura, T., and S. Taneya. 1975. Electron microscopic observation of casein particle in cheese. J. Electron Microsc. (Tokyo) 24:115-117. https://doi.org/10.1093/oxfordjournals.jmicro.a049955.

Lee, J., J.-H. Lee, S. R. Paik, B. Yeom, and K. Char. 2019. Thermally triggered self-assembly of $\kappa$-casein amyloid nanofibrils and their nanomechanical properties. Polymer (Guildf.) 179:121626. https:/ /doi.org/10.1016/j.polymer.2019.121626.

Lee, S. K., R. J. Buwalda, S. R. Euston, E. A. Foegeding, and A. B. McKenna. 2003. Changes in the rheology and microstructure of processed cheese during cooking. Lebensm. Wiss. Technol. 36:339 345. https://doi.org/10.1016/S0023-6438(03)00012-4.

Lenze, S., A. Wolfschoon-Pombo, K. Schrader, and U. Kulozik. 2019. Effect of compositional factors and processing conditions on the creaming reaction during process cheese manufacturing. Food Bioprocess Technol. 12:575-586. https://doi.org/10.1007/s11947-019 $-2234-6$.

Pan, K., and Q. Zhong. 2015. Amyloid-like fibrils formed from intrinsically disordered caseins: Physicochemical and nanomechanical properties. Soft Matter 11:5898-5904. https://doi.org/10.1039/ C5SM01037C

Rayan, A. A., M. Kalab, and C. A. Ernstrom. 1980. Microstructure and rheology of process cheese. Scan. Electron Microsc. 3:635-643.

Röck, S. M. 2010. Untersuchungen von Strukturbildungsvorgängen in komplexen Milchsystemen - dargestellt am Beispiel von Schmelzkäse. Dissertation. Technical University Munich, Germany.

Tamime, A. Y., M. Kalab, G. Davies, and M. F. Younis. 1990. Microstructure and firmness of processed cheese manufactured from cheddar cheese and skim milk powder cheese base. Food Struct. 9:23-37.

Taneya, S., T. Kimura, T. Izutsu, and W. Buchheim. 1980. The submicroscopic structure of processed cheese with differerent melting properties. Milchwissenschaft 35:479-481.

Thorn, D. C., H. Ecroyd, M. Sunde, S. Poon, and J. A. Carver. 2008. Amyloid fibril formation by bovine milk $\alpha_{\mathrm{S} 2^{-}}$-casein occurs under physiological conditions yet is prevented by its natural counterpart, $\alpha_{S 1}$-casein. Biochemistry 47:3926-3936. https://doi.org/10 $.1021 /$ bi701278c.

Thorn, D. C., S. Meehan, M. Sunde, A. Rekas, S. L. Gras, C. E. MacPhee, C. M. Dobson, M. R. Wilson, and J. A. Carver. 2005. Amyloid fibril formation by bovine $\kappa$-casein and its inhibition by the molecular chaperones $\alpha_{S^{-}}$and $\beta$-casein. Biochemistry 44:17027-17036. https://doi.org/10.1021/bi051352r.

Treweek, T. M., D. C. Thorn, W. E. Price, and J. A. Carver. 2011. The chaperone action of bovine milk $\alpha_{\mathrm{S1}^{-}}$and $\alpha_{\mathrm{S} 2^{-}}$-caseins and their associated form $\alpha_{\mathrm{S}}$-casein. Arch. Biochem. Biophys. 510:42-52. https://doi.org/10.1016/j.abb.2011.03.012.

Vollmer, A. H., N. N. Youssef, J. A. Powell, and D. J. McMahon. 2019. Progressive ultrastructural changes in the casein matrix during the ripening of inadequately acidified feta cheese. J. Dairy Sci. 102:7734-7746. https://doi.org/10.3168/jds.2019-16395.

Zehren, V. L., and D. D. Nussbaum. 1992. Process Cheese. Schreiber Foods.

\section{ORCIDS}

Almut H. Vollmer () https://orcid.org/0000-0001-5647-6524 Ulrich Kulozik @ https://orcid.org/0000-0001-9598-9242 